\title{
Kalıcı Mıknatıslı Senkron Generatörlü Rüzgâr Enerjisi Dönüşüm Sistemlerinde Maksimum Güç Kontrolünün Akıllı Yapı Tabanlı Modellemesi
}

\author{
Hasan Bektaş Perçin ${ }^{*}$, Abuzer Çalışkan ${ }^{2}$ \\ 1* Frrat Üniversitesi, Mühendislik Fakültesi, Elektrik Elektronik Mühendisliği Bölümü, Elazı̆ğ, Türkiye, (ORCID: 0000-0001-8968-969X), hbpercin@ firat.edu.tr \\ ${ }^{2}$ Frrat Üniversitesi, Mühendislik Fakültesi, Elektrik Elektronik Mühendisliği Bölümü, Elazı̆̆, Türkiye (ORCID: 0000-0001-8262-7912), acaliskan@ firat.edu.tr
}

(2nd International Conference on Access to Recent Advances in Engineering and Digitalization (ARACONF)-10-12 March 2021)

(DOI: $10.31590 /$ ejosat.898952)

ATIF/REFERENCE: Percin, H.B., Caliskan, A., (2021). Kalıcı Mıknatıslı Senkron Generatörlü Rüzgâr Enerjisi Dönüşüm Sistemlerinde Maksimum Güç Kontrolünün Akıllı Yapı Tabanlı Modellemesi. Avrupa Bilim ve Teknoloji Dergisi, (24), $219-225$.

$\ddot{0} \mathbf{z}$

Rüzgâr enerjisi, elektrik üretiminde kullanımı giderek artan yenilenebilir bir enerji kaynağıdır. Rüzgârdan elektrik enerjisinin üretiminde kullanılan sistemin verimliliği, uygun elemanların ve kontrol tekniğinin seçimine bağlıdır. Bu tür dönüşüm sistemlerinde, değişken hızlı rüzgâr türbinleriyle doğrudan bağlantılı olarak kullanılabilen kalıcı mıknatıslı senkron generatörler ön plana çıkmaktadır. Bu generatörler, elektriksel kayıpları ve mekanik bileşenlere bağımlılığı azaltarak genel sistem performansını yükseltme özelliğine sahiptir. Dönüşüm sistemlerinde sistemin anlık çalışma hızı ayarlanarak yapılan kontrol maksimum güç noktası izleme kontrolü olarak tanımlanmaktadır. Bu kontrol, anlık rüzgâra göre sistemin üretim verimliliği en üst düzeyde tutarak daha uzun ömürlü ve daha az maliyetli enerji üretimi sağlayabilir. Bu çalışmada, rüzgâr enerjisi dönüşüm sistemi ve maksimum güç noktası izleme kontrolünün temel prensibi açıklanmış. Akıllı kontrol yapısı olarak tanımlanan bulanık mantık kontrolü Matlab/Simulink ortamında modellenerek çeşitli sistem büyüklükleri üzerinden kontrol yapısının analizi gerçekleştirilmiştir. Bu kontrol yapısı, değişken rüzgâr profiline göre dönüşüm sisteminin daha kararlı ve daha verimli çalışmasını sağlamıştır.

Anahtar Kelimeler: Rüzgâr Enerjisi, Kalııı Mıknatıslı Senkron Generatör, Modelleme, Maksimum Güç Noktası İzleme, Bulanık Mantık Kontrol.

\section{Intelligent Structure Based Modelling of Maximum Power Control in Wind Energy Conversion Systems with Permanent Magnet Synchronous Generator}

\begin{abstract}
Wind energy is a renewable energy source increasingly used in electricity generation. System efficiency in electrical energy production from wind depends on the selection of suitable components and control technique. In this type of conversion systems, Permanent magnet synchronous generators, which can be used directly connected to variable speed wind turbines, come to the fore. These generators have the ability to increase overall system performance by reducing electrical losses and dependency on mechanical components. The control performed in conversion systems by adjusting the instant operating speed of the system is defined as the maximum power point tracking control. This control can provide more durable and less costly energy production by keeping the production efficiency of the system at the highest level according to the instant wind. In this study; wind energy conversion system and basic principle of maximum power point tracking control were explained. Fuzzy logic control, defined as an intelligent control structure, was analyzed based on various system parameters through modelling in Matlab/Simulink environment. This control structure enabled the conversion system to operate more stable and more efficiently according to the variable wind speed profile.
\end{abstract}

Keywords: Wind Energy, Permanent Magnet Synchronous Generator, Modelling, Maximum Power Point Tracking Control, Fuzzy Logic Control.

\footnotetext{
*Sorumlu Yazar: hbpercin@ firat.edu.tr
} 


\section{Giriş}

Elektrik enerjisi üretiminde kullanılan fosil yakıtlar; sera gazı salınımı, hava kalitesinde bozulma, su ve çevre kirliliği gibi birçok soruna sebep olmaktadır. Bu problemler, çevresel etkisi daha az olan yenilenebilir enerji kaynaklarına olan ilgiyi arttırmaktadır.

Yenilenebilir enerji türlerinden yaygın olarak kullanılanlardan biri de rüzgâr enerjisidir. Gelişen teknolojiyle birlikte uygun maliyetli enerji dönüşüm sistemleriyle kullanılabilmeleri, sera gazı etkisi yaratmamaları gibi avantajlara sahiptir. Ancak rüzgârın sabit bir kaynak olmayıp değişkenlik gösteren yapıda olması bu enerji için kullanılan dönüşüm sistemlerinin iyi bir şekilde kontrolünü gerektirir.

Rüzgârdan elektrik enerjisi elde etmek için kullanılan rüzgâr enerjisi dönüşüm sistemi (REDS)'ler, rüzgârdaki kinetik enerjiyi önce mekanik enerjiye daha sonra da elektrik enerjisine dönüştüren sistemlerdir. REDS'nin iyi bir verimlilikle kullanılabilmesi hem rüzgârdan maksimum oranda yararlanma hem de sistemin uzun süre kullanılması açısından önemlidir. Son yıllarda gelişen teknolojiyle değişken hızlı türbinlerle uyumlu, kalıcı mıknatıslı senkron generatör (KMSG) içeren REDS'ler ön plana çıkmaktadır. Rotorlarında bulunan kalıcı mıknatıslarla harici bir uyartıma ihtiyaç duymadan çok kutuplu tasarlanarak doğrudan türbin bağlantılı kullanılabilmeleri, güçlü mekanik karakteristikleri ve her hiz seviyesinde güç üretebilmeleri REDS'lerde kullanımlarını yaygınlaştırmıştır.

REDS'ler için üretim verimliliğini esas alan çalışmalarda anlık rüzgârdan maksimum seviyede yararlanabilmek adına kullanılan yöntemler maksimum güç noktası izleme (MGNI) yöntemleri olarak adlandırılmaktadır. Değișken hızlı REDS'ler için bu yöntemler, esasında kullanılan genratörün çalışma hızının belirli hız aralıklarında rüzgâr hızına göre ayarlanmasına göre çalışmaktadır.

MGNİ için kullanılan kontrol yöntemleri, generatör ve yük arasındaki ara yüzlere göre farklılık gösterebilmektedir. Bu ara yüz yapılarından biri de kıyıcı içeren ara yüzlerdir. Kıyıcının doluluk oranı üzerinden maksimum gücün anlık olarak elde edilmesiyle değişken rüzgâr hızlarında MGNI kontrolü gerçekleştirilebilmektedir. $\mathrm{Bu}$ prensibe göre çalışan klasik kontrol yapısı olarak tanımlanabilecek PID kontrolör tabanlı çalışmalarda [1-3] kontrol yapısının REDS'nin anlık çalışma noktasını ayarlayacak şekilde çalışması sağlanmış. Farklı kontrol yapıları için giriş çıkış değişkenlerine göre çalışmalar gerçekleştirilmiştir. Ancak bu tekniklerin hızlı değişimler karşısında düşük performansları söz konusudur. REDS'ler gibi nonlineer kontrol özelliği gösteren yapılarda MGNİ kntrolü için akıllı yap1 olarak tanımlanabilecek yöntemlerden de yararlanılmaktadır. Bu yapıların en önemli özelliği uyarlanabilir ve hızlı kontrol imkânı verebilmeleridir. Akıllı yapılardan bulanık mantığı esas alan çalışmalarda [4-7] farklı bulanık mantık kontrol tasarımlarıyla değişken rüzgâr hızlarında MGNI kontrolü geçekleştirilmiş. Farklı şekillerde kontrol yöntemi analiz edilmiştir.

$\mathrm{Bu}$ çalışmada değişken hızlı rüzgâr türbinleriyle uyumlu KMSG'li REDS için enerji dönüşümü sistem büyüklükleri üzerinden açıklanmış. Bulanık mantık yapısını esas alan MGNI kontrolünün genel bir sistem modeliyle birlikte Matlab/Simulink ortamında modellemesi gerçekleştirilmiştir. Kullanılan yöntemin çeşitli büyüklükler ve grafikler üzerinden performansı değerlendirilmiştir.

\section{Materyal ve Metot}

\subsection{Rüzgâr Enerjisi Dönüşüm Sistemi}

REDS'ye ait genel dönüşüm şeması Şekil 1'de görülmektedir

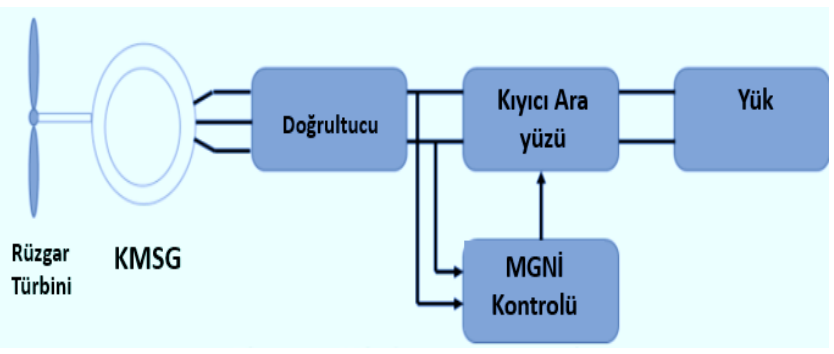

Şekil 1 REDS genel dönüşüm şeması

Şekil 1'e göre rüzgâr türbininde elde edilen mekanik enerji generatör tarafindan elektrik enerjisine dönüştürülür. KMSG'den sonra gelen doğrultucu çıkışında rüzgardaki değişimlere göre değişken yapıda bir doğru gerilim elde edilir. Burada kullanılan kıyıcı ara yüzünün türüne göre değişken yapıdaki doğrultulmuş gerilim kıyıcı çıkışında belirli bir seviyeye ayarlanır. Bu gerilim sabit gerilimle beslenen yüklere sağlanabileceği gibi inverter aracılığıyla alternatif gerilim olarak da kullanılabilir.

\subsubsection{Rüzgâr Türbini Modeli}

REDS'de sisteme ait bileşenler üzerinden elde edilen matematiksel modeller, enerji dönüşümü ve MGNİ kontrolünü anlayabilmek adına önemlidir [8]. Enerji üetiminin ilk aşamasında kullanılan türbin tarafından anlık rüzgâra göre elde edilen mekanik güç matematiksel olarak Eşitlik 1'deki gibi ifade edilir.

$$
P_{\text {Mekanik }}=\frac{1}{2} \times p \times C_{P} \times A \times V_{R}^{3}
$$

Burada $p$ hava yoğunluğu, $A$ türbin kanatlarının taradığı alan, $V_{R}$ rüzgâr hızı olarak tanımlanır. Eşitlikteki $C_{P}$ terimi ise REDS'lerde türbinden elde edilen mekanik gücün rüzgârın mevcut gücüne oranı olarak tanımlanabileceği gibi rüzgârdan ne kadar oranda faydalanılabildiğini gösteren güç (verimlilik) katsayısıdır [8-10]. Bu katsayı iki farklı değişkene göre Eşitlik 2'deki gibi ifade edilir.

$$
\begin{aligned}
& C_{P}(\lambda, \beta)=C_{1}\left(\frac{C_{2}}{\lambda_{i}}-C_{3} \times \beta-C_{4}\right) e^{-\left(C_{5} / \lambda_{i}\right)}+C_{6} \times \lambda \\
& \frac{1}{\lambda_{i}}=\frac{1}{\lambda+0.08 \beta}-\frac{0.035}{\beta^{3}+1}
\end{aligned}
$$

$C_{1-6}$ ile ifade edilen parametreler, türbinlerin tasarımına özgü sabit değerlerdir. $\beta$ ise yüksek hızlarda türbinin zarar görmesini engelleyecek şekilde devreye girebilen kanat açısı, $\lambda$ ise kanat uç hız oranı (KHO) olarak tanımlanır. $\mathrm{Bu}$ oran matematiksel olarak Eşitlik 3'deki gibi ifade edilir.

$$
\lambda=\frac{w_{M} \times R}{V_{R}}
$$

Burada $\mathrm{R}$ türbin kanat yarıçap1, $w_{M}$ türbinin ve türbinle doğrudan bağlantılı KMSG'nin rotor hızı, $V_{R}$ ise rüzgâr hızıdır. Güç katsayısı en optimal KHO ve kanat açısı değerlerinde maksimum 0.5926 değerini almaktadır. Bu maksimum değer aynı zamanda betz limiti olarak da adlandırılmaktadır. Bu değere 
göre rüzgârdan elde edilebilecek maksimum mekanik güç teorik olarak rüzgâr gücünün \%59,26'sına denk gelir. Ancak kayıplar, aerodinamik özelliklerden dolayı günümüzdeki rüzgâr türbinlerinde türbin dönüşüm verimliliği \%40-50 arasındadır. Bu da en uygun koşullarda güç kasayısının 0.4 ile 0.5 arasında değer alacağını gösterir.

Farklı kanat açısı (beta) değerlerine göre güç katsayısı ve KHO arasındaki değişimi gösteren grafik Şekil 2'de görülmektedir.

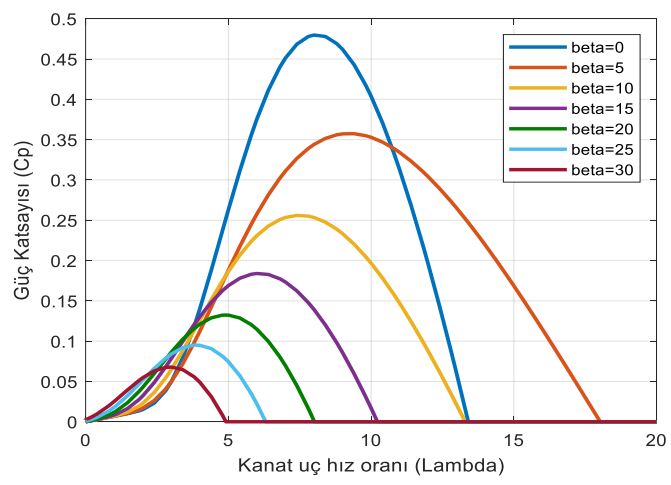

Şekil 2. Güç katsayısı- KHO değişimi

Güç katsayısı Cp'nin en yüksek seviyede tutulabilmesi, türbinden en yüksek verimlilikte güç elde edilebilmesini sağlar Şekil 2'ye göre, nominal rüzgâr hızı değerinin altında kanat açısı değerinin en küçük değerde, KHO'nun uygun değerde tutulmasıyla güç katsayısı maksimum değerini almaktadır. Eşitlik 3'teki ifadeye göre KHO değeri, türbin kanat yarıçap1 ve rotor hızına bağlıdır. Denklemde kullanılan türbin kanat yarıçapı, sabit bir değer olduğundan değişen rüzgâr hızlarına göre rotor hızını ayarlamak suretiyle KHO ve güç katsayısının en uygun değerlerde tutulması, hız kontrolünün dolayısıyla anlık maksimum güç kontrolünün temelini oluşturur. Ayrıca Şekil 2'ye göre kanat açısı değerinin arttırılmasıyla güç katsayısının düşmesi ise anlık gücün anma gücünden daha yüksek seviyelere çıktığında gücün sınırlanmasıyla sistemde koruma işleminin yapılabileceğini de gösterir [11]. Şekil 3'te değişen rüzgâr hızlarına göre türbin çıkış gücünün rotor hızına göre değişimi görülmektedir

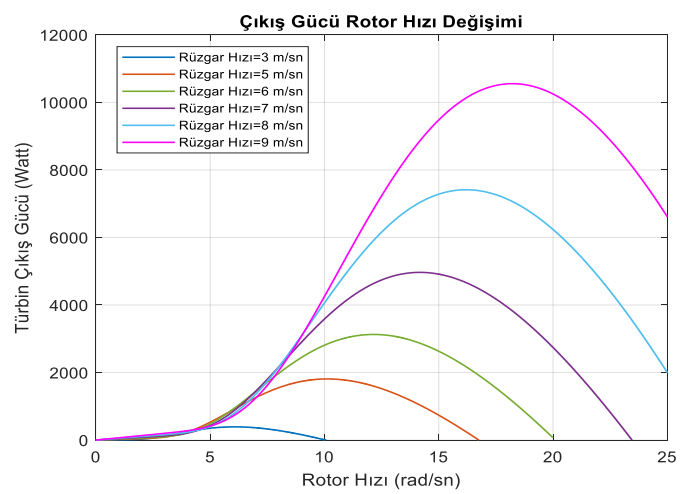

Şekil 3. Türbin çıkış gücünün rotor hızına göre değişimi

Şekil 3 incelendiğinde çıkış gücü, belirli rotor hızlarında maksimum değeri alabilmektedir. Kullanılacak farklı MGNI yöntemleriyle anlık rotor hızının rüzgâr hızına göre ayarlamasıyla KHO'nun ve güç katsayısının değerleri de ayarlanarak sistem verimliliği maksimum seviyede tutulabilir.

\subsubsection{Arayüz Modeli}

Türbinden gelen mekanik gücün anlık rüzgâra göre değişken yapıda olmasından dolayı generatör çıkışında elde edilen değişken yapıdaki gerilimin yük ile generatör arasındaki arayüz yapısıyla belirli seviyeye ayarlanarak kullanılmasını gerekir. $\mathrm{Bu}$ çalışmada kullanılan doğrultucu ve kıyıcı devresinden oluşan örnek arayüz Şekil 4 'te görülmektedir.

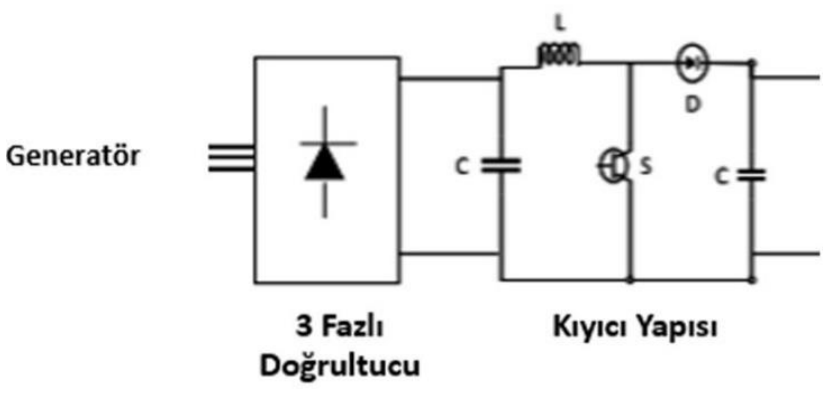

Şekil 4. Doğrultucu kıyıcı arayüz şeması

Generatör ve doğrultucu çıkışındaki akım ve gerilimler arasındaki bağıntı Eşitlik 4 ve 5'teki gibi ifade edilir.

$$
\begin{aligned}
& V_{D C}=\frac{3 \sqrt{2}}{\pi} V_{L L}=\frac{3 \sqrt{6}}{\pi} V_{g e n} \\
& I_{D C}=\frac{\pi}{\sqrt{6}} I_{\text {gen }}
\end{aligned}
$$

Eştliklerde $V_{g e n}, I_{g e n}$ generatör gerilimi ve akımını; $V_{D C}$ ve $I_{D C}$ doğrultucu çıkış gerilimi ve akımını ifade etmektedir. Doğrultucu çıkışındaki gerilimin belirli bir seviyede tutulabilmesi, sistemin beslediği yük, inverter ve depolama elemanları açısından önemlidir. Kullanılan kıyıcı devreleri, doğrultucu çıkışından gelen gerilime göre çıkışında istenen seviyede gerilim sağlayabilecek şekilde çalışabilir. Bu çalışmada kullanılan yükselten (boost) tip kıyıcı devresinin anlık kontrolüyle doğrultucudan gelen gerilime göre çıkıșta daha yüksek seviyede bir gerilim elde edilebilir. Şekil 5'te yükselten tip (boost) kıyıcı devre şeması görülmektedir.

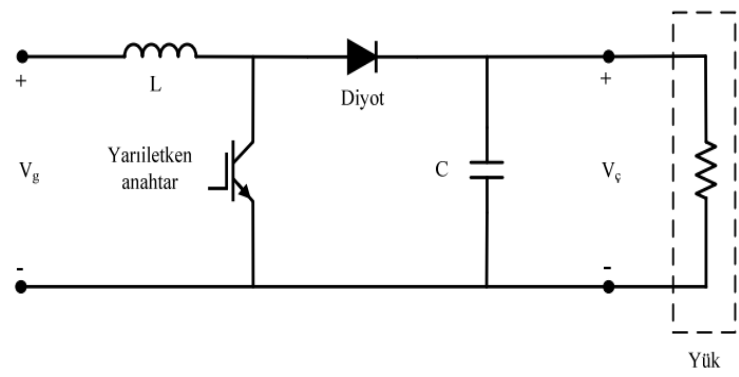

Şekil 5. Yükselten Tip (Boost) Kıyıcı Devre Şeması

Kıyıcıda kullanılan yarı iletken anahtarın iletim ve kesim sürelerine göre Eşitlik 6 ve 7 elde edilir.

$$
\begin{aligned}
& T_{S}=t_{\text {On }}+t_{\text {Off }} \\
& d=\frac{t_{\text {On }}}{T}
\end{aligned}
$$

$\mathrm{Bu}$ eşitliklere göre $T_{S}$ anahtarlama periyodunu, $t_{O n}$ ve $t_{O f f}$ sırasıyla anahtarın iletimde ve kesimde kalma sürelerini, $d$ ise anahtarlama sürelerine göre elde edilen doluluk oranı (görev periyodu)'dır. Bu değer 0 ile 1 arasında bir değerdir. Kıyıcının uygun şekilde çalışması doluluk oranının kontrolüyle doğrudan ilgilidir. Doluluk oranına göre yükselten tip kıyıcı devresinde giriş ve çıkış gerilimleri arasındaki bağıntı Eşitlik 8'deki gibidir. 


$$
\frac{V_{c ̧ l k l s}}{V_{\text {Giriş }}}=\frac{1}{1-d}
$$

Girişine uygulanan gerilim $\left(V_{\text {Giriș }}\right)$ sabit ya da değişken olmasına bakılmaksızın görev periyodunun anlık kontrolüyle gerilim ayarı yapılabileceği Eşitlik 8'de görülmektedir. Kullanılan kontrol tekniğiyle kıyıcının doluluk oranıyla kıyıcı giriş gerilimi istenen şekilde ayarlanabilirse generatörde indüklenen gerilimin hızıyla orantılı olduğu düşünüldüğünde dolaylı yoldan generatörün hızı da ayarlanabilir. Bu kontrol mantığı, kıyıcılı arayüz içeren REDS'de MGNİ kontrolünün temel prensibidir [12].

Kullanılan kontrol yapısının yanında yükselten tip kıyıcının kontrol yapısına uygun kararlılıkta çalışabilmesi, kıyıcı'da kullanılan endüktans (L), kondansatör (C) ve yarı iletken elemanın anahtarlama frekansının uygun şekilde seçimine bağlıdır. Kıyıcıyı devresinde kullanılacak $\mathrm{L}$ ve $\mathrm{C}$ değerleri, Eşitlik 9 ve 10'daki gibi hesaplanır.

$$
\begin{aligned}
& L=\frac{V_{g(\text { Min })^{* d}}}{\Delta I_{L^{*} f_{S}}} \\
& C=\frac{I_{\mathcal{C}(M a x)^{* d}}}{\Delta V_{C} * f_{S}}
\end{aligned}
$$

Eşitlikler giriş gerilimimin minimum değeri $V_{g(\text { Min })}$ çıkış akımının maksimum değeri $I_{c ̧ \text { (Max) }}$, kıyıcının anahtarlama frekansı $f_{S}$ ile gösermektedir. $\Delta I_{L}$ ve $\Delta V_{C}$ 'nin endüktans akımı ve kondansatör geriliminde yüzdesel olarak ne kadarlık dalgalanmaya izin verilebileceğini gösteren yüzdesel değerler olup yapılan hesaplamalar uygun devre elemanlarının seçimine ve bunlara uygun kıyıcı devresinin tasarımına imkan verir [12].

\subsection{MGNI Yöntemleri}

REDS'de kullanılabilen MGNİ kontrol yöntemleri; ek donanım gereklilikleri, sistem parametrelerinden bağımsız olup olmamaları, uygulanma şekilleri gibi çeşitli kriterlere göre sınıflandırılabilir. Uygulanma şekillerine göre dolaylı, doğrudan, akıllı yapı tabanlı yöntemler bulunmaktadır. Dolaylı ve doğrudan yöntemler kullandıkları sistem parametresinin türüne göre tanımlanmaktadırlar. Akıllı yapı tabanlı yöntemler ise bulanık mantık, yapay sinir ağları, optimizasyon teknikleri gibi yöntemlerin MGNİ kontrolü için kullanıldığı tekniklerdir. [13].

Doğrudan ve dolaylı MGNİ yöntemlerinin ek donanım ihtiyaçları, karmaşık tasarımları ve yavaş çalışma hızları gibi dezavantajları, nonlineer yapıdaki REDS'ler için anlık koşullara göre uyarlanabilir performans sunan akıllı yapı tabanlı MGNI yöntemlerinin kullanımına zemin hazırlamıştır [14]. Bu tip yöntemlerden bulanık mantık yöntemi, uzman bilgisi ve bu bilgiye göre oluşturulan sözel olarak ifade edilen değişkenler üzerinden çalışan ve farklı aşamalardan meydana gelen kontrol yapıs1 olarak tanımlanabilir. REDS'lerde farklı sistem büyüklüklerini kullanarak çalışan bulanık mantık yapısının prensip şeması Şekil 6'da görülmektedir.

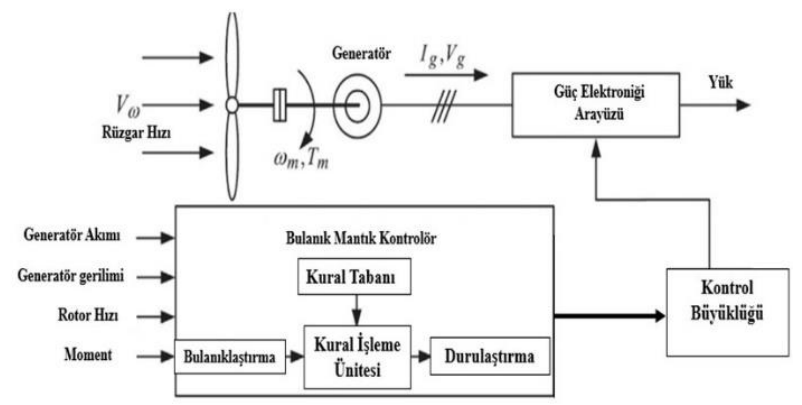

Şekil 6 Bulanık mantık tabanlı MGNI kontrolü

Bulanık mantıklı MGNİ yapıları, genellikle çok girişli ve tek çıkışlı olarak tasarlanabilirler. Seçilen değişkenler farklı türde olabileceği gibi bu büyüklüklerin birbirlerine göre değişimleri de kullanılabilir. Mekanik büyüklükler yerine elektriksel büyüklüklerinin kullanımı ek donanım ve maliyet açısından fayda sağlayabilir. Kontrolörün performansını kullanıcı bilgisi, kullanılan sözel değişkenler, bunlara göre oluşturulan üyelik fonksiyonları ve kural tabanı belirler $[15,16]$

Tablo 1. Çalışmada Kullanılan Türbin ve Generatör Parametreleri

\begin{tabular}{l|l|l|l}
\hline Türbin Parametreleri & & KMSG Parametreleri & \\
\hline Rotor Yarıçapı & $4 \mathrm{~m}$ & Stator Direnci & $0.425 \Omega$ \\
\hline $\boldsymbol{p}$ (Hava Yoğunluğu) & $1.2 \mathrm{Kg} / \mathrm{m} 3$ & Armatür Endüktansı & $0.000835 \mathrm{H}$ \\
\hline Kanat Açısı & $0^{\circ}$ & Akı Bă̆ & $0.433 \mathrm{~Wb}$ \\
\hline Optimal KHO & 8.4 & Atalet (J) & $0.01197 \mathrm{~kg} \cdot \mathrm{m}^{2}$ \\
\hline Optimal Güç katsayısı & 0.48 & Sürtünme (Viskoz) Katsayısı (B) & $0.001189 \mathrm{Nms}$ \\
\hline Yük & $50 \Omega$ & Kutup Çifti & 8 \\
\hline
\end{tabular}

\section{Araştırma Sonuçları ve Tartışma}

$\mathrm{Bu}$ çalışmada KMSG içeren değişken rüzgâr hızlarında kullanıma uygun REDS modeli, Tablo 1 'de verilen parametreler üzerinden gerçekleştirilmiştir. Bulanık mantıklı yapı üzerinden MGNI kontrolü gerçekleştirilmiştir. Kullanılan REDS'ye ait Simulink modeli Şekil 7'de görülmektedir. 


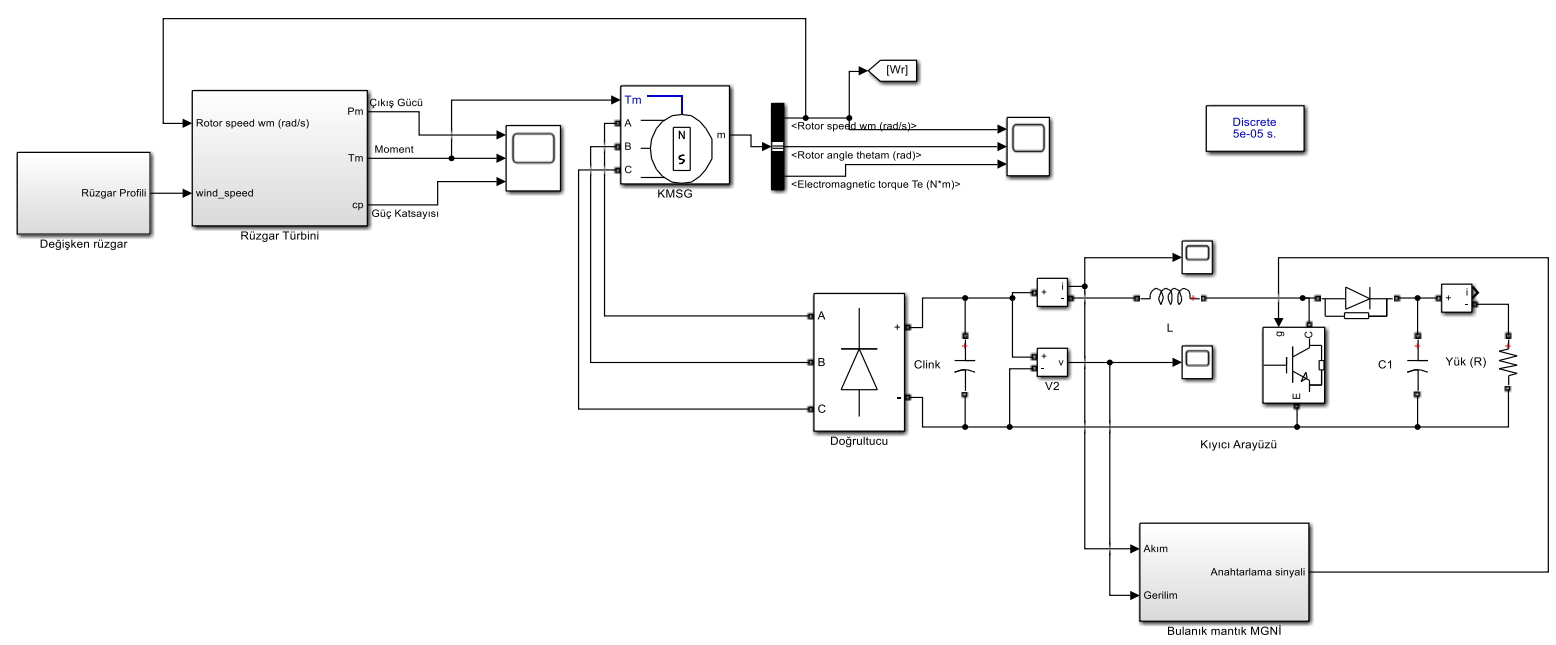

\section{SSekil 7 REDS Matlab/Simulink modeli}

Şekil 7'deki modele göre değişken rüzgâra göre rüzgâr türbininden anlık üretilen momentin KMSG'ye uygulanmasıyla generatör çıkışında rüzgarla uyumlu olarak üretilen gerilim, kontrolsüz doğrultucu tarafından doğrultulur ve kıyıcı devreli arayüze aktarılır. Kullanılan bulanık mantık MGNİ bloğu, kıyıcı devresinin kontrolü için kullanılır. Modelde kullanılan türbin, generatör için hazır bloklardan yararlanılabileceği gibi sistem büyüklüklerin matematiksel modelleri üzerinden de oluşturulabilir. Çalışmada kullanılan yükselten tip (boost) kıyıcı devresini oluşturan temel elemanların seçiminde kullanılan değerler önceki bölümde verilen eșitliklere göre hesaplanabilir.

Çalışmada MGNİ kontrolüne odaklanıldığından güç katsayısının maksimum değerini elde edebilmek için kanat açısı minimum olacak şekilde $0^{\circ}$ olarak alınmıştır. REDS için en uygun KHO'nun değeri 8.4 güç katsayısının buna karşılık 0.48 olduğu belirlenmiştir. Kulanılan tekniklerle bu parametrelerin anlık değerlerinin bu değerlere yakın değişimler göstermesi verimlilik adına temel hedeftir.

Akıllı yapı MGNI kontrolü olarak kullanılan bulanık mantık yöntemine göre oluşturulan simulink modeli Şekil $8^{\text {'de }}$ görülmektedir.

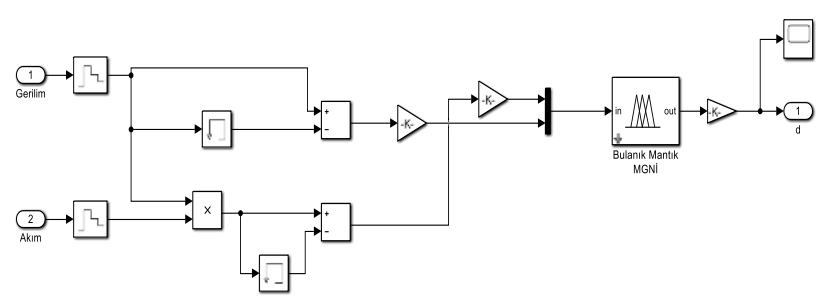

\section{Sekil 8 Bulanık mantık MGNİ modeli}

Şekil 8'deki modele göre giriş değişkenleri olarak kıyıcı girişinde elde edilen akım ve gerilimlere göre elde edilen gücün değiş̧imi $(\Delta \mathrm{P})$ ve generatör geriliminin değişimi $(\Delta \mathrm{V})$ seçilmiş, bulanık kontrol yapısının çıkış değişkeni olarak kıyıcının doluluk oranı alınmıştır. $\mathrm{Bu}$ oran daha sonra belirli bir anahtarlama sinyaliyle kıyıcı devresine anlık uygulanır. Hem değişimleri elde edebilme hem de modeli optimize edebilmek için farkı bloklardan yararlanılmıștır. Seçilen giriş değişkenleri ve kontrol değişkenine göre bulanık mantık tabanlı MGNI kontrolü için oluşturulan üyelik fonksiyonları ve kural tabanı Şekil 9'da görülmektedir.

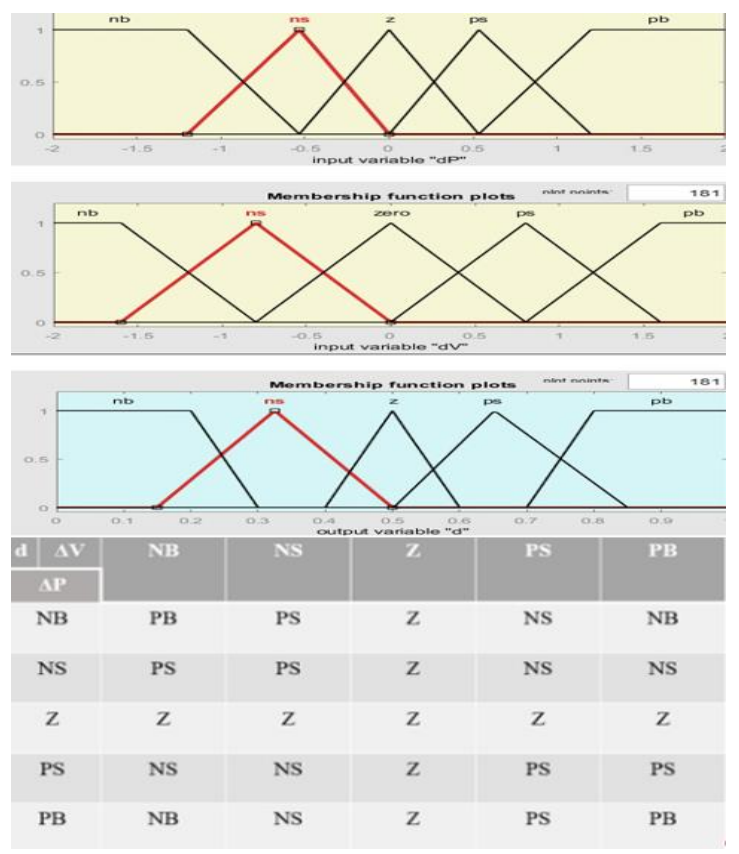

Şekil 9 Bulanık mantık üyelik fonksiyonları ve kural tabanı

Şekil 9'da Kural tabanında belirtilen değişkenler, NB (Negatif Büyük), NS (Negatif Küçük), Z (Sıfir), PS (Pozitif Küçük), PB (Pozitif Büyük) şeklindedir. Sözel olarak ifade edilen değişkenlere göre trapezoid ve üçgen üyelik fonksiyonları kullanılmıştır. Kural tabanı güç ve gerilimdeki değişimlerin negatif ya da pozitif olması ve bu değişimlerin büyüklüğüne göre doluluk oranını artıracak ya da azaltacak şekilde bulanık mantık yapısını çalıştıracak şekilde oluşturulmuştur.

Kullanılan akıllı yapının performansını ölçebilme adına türbin girişinden uygulanan değişken rüzgâr profili Şekil 10'da görülmektedir. 


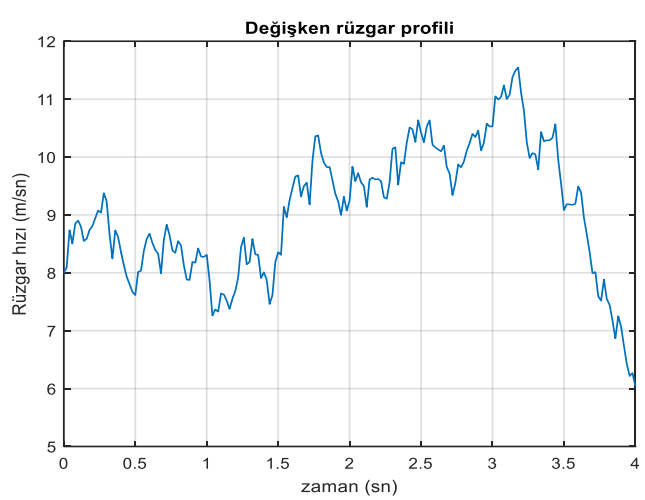

Şekil 10 Değişken rüzgâr profili

Kullanılan bulanık mantık yapısıyla değişen rüzgâr hızlarına göre doluluk oranındaki değişim Şekil 11'deki gibidir.

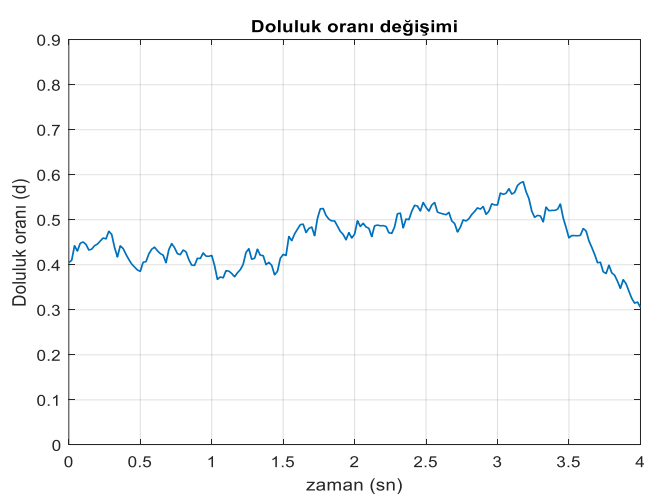

Şekil 11 Anlık doluluk oranı değişimi

Rüzgâr hızı değişimleriyle uyumlu doluluk oranı değişimi, kontrol yapısı tarafından sağlanmıştır. Değişimler hedeflendiği gibi anlık rüzgâra göre doluluk oranını artırarak ya da azaltarak çalışmaktadır.

Kullanılan kontrolün performansının değerlendirmesinde KHO ve güç katsayılarının değişimi önemlidir. Bulanık mantık tabanlı MGNI kontrolü için KHO değişimi Şekil 12'de görülmektedir.

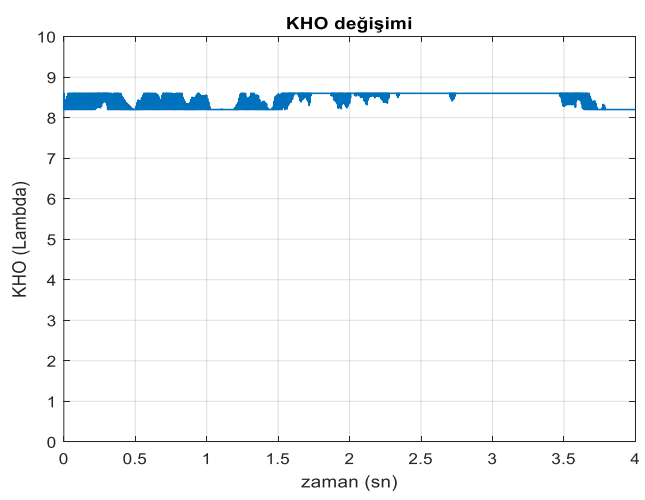

Şekil 12 Bulanık mantık yapısı KHO değişsimi

Şekil 12'deki KHO değişimi incelendiğinde referans KHO değeri 8.4 dolaylarında bir değişim elde edilmiştir. Bu değişime göre güç katsayısındaki değişim Şekil 13 'te görülmektedir.

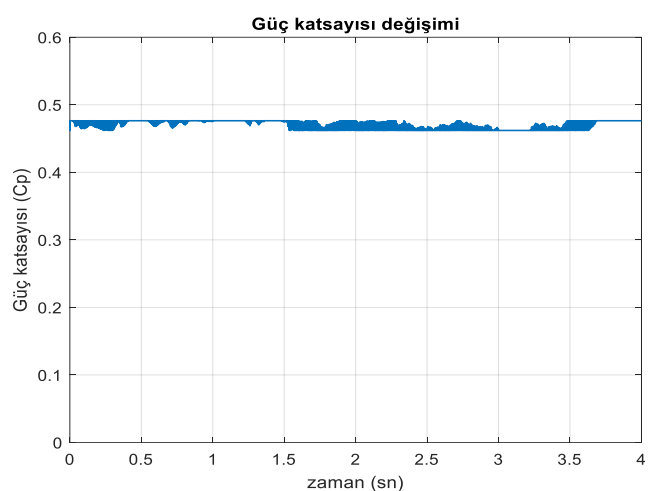

Şekil 13 Bulanık mantık yapısı güç katsayısı değişimi

Güç katsayısı değişimi, KHO’daki değişim gibi referans değer 0.48 'e yakın bir değişim göstermiştir. Bu da kontrol yapısının değişen rüzgâra göre iyi performans gösterdiğini kanıtlamıştır. Değişen rüzgâr hızlarına göre MGNİ kontrolü, anlık hız kontrolünü sağlayacak şekilde çalışmaktadır. Bulanık mantık yapısı için rotor hızının, hesaplanan referans hıza göre değişimi Şekil 14'de görülmektedir.

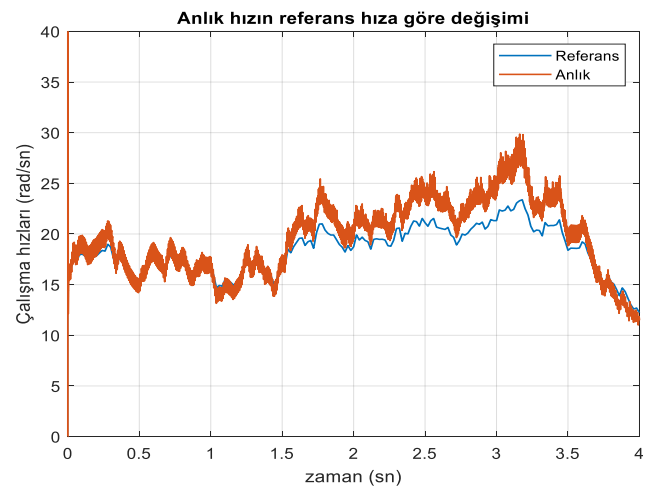

Şekil 14 Bulanık mantık yapısı rotor hızı değişimleri

Şekil 14 incelendiğinde anlık rotor hızının referans hızdaki değişimlerle uyumlu şekilde değiştiği görülmektedir. Referans hızdaki değişimlerle benzer değerlerde değişim gösteren çalışma hızı, kullanılan tekniğin iyi performansını kanıtlayan başka bir sonuçtur.

Kullanılan bulanık mantık yapısı için türbin çıkış gücü değişimi ise Şekil 15'te görülmektedir.

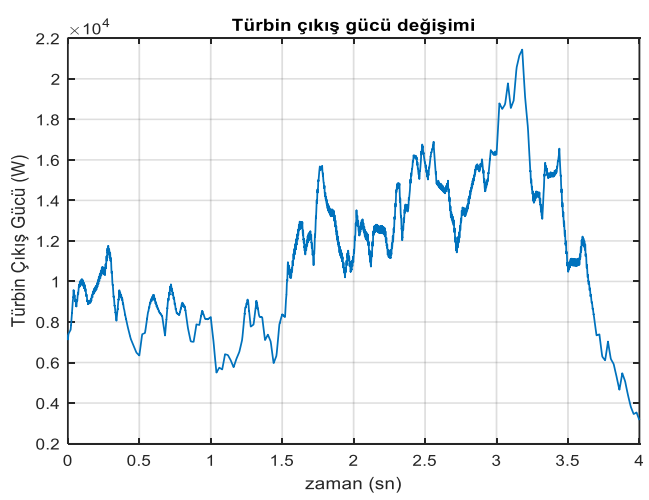

Şekil 15 Bulanık mantık yapısı türbin çıkış gücü değiş̧imi

Şekil 15'te rüzgâr hızındaki değişimlerle uyumlu güc değişimi, kullanılan bulanık mantık yapısının REDS'de MGNi kontrolü için iyi bir kontrol performansı verdiğini göstermiştir. 


\section{Sonuç}

Anlık rüzgâra göre sistem verimliliğinin en üst seviyede tutulması sağlanarak maliyetlerin düşürülmesi, daha uzun ömürlü, daha yüksek seviyede enerji üretimi sağlanabilir. Farklı rüzgâr koşullarına göre REDS'nin verimliliğini ayarlayan MGNI kontrolü için kullanılabilecek birçok teknik olmasına rağmen anlık koşullara kolay uyum sağlayabilen, esnek ve hızlı çalışma imkânı sunan, ek donanım ihtiyacını ortadan kaldırabilme imkânı veren akıllı yapılar son yıllarda öne çıkmaktadır. Bu akıllı yapılardan bulanık mantığı esas alan MGNI kontrolü, bu çalışmadaki REDS modeliyle analiz edildiğinde verimlilik açısından referans kabul edilen değerlere yakın, kararlı ve verimli çalışmayı sağlamıştır. Sağladığı faydalar hızlı değişimlere maruz kalabilen KMSG'li REDS'ler için maksimum güç kontrolünde bulanık mantık yapısının uygunluğunu kanıtlamıştır.

$\mathrm{Bu}$ çalışmada kullanılan yöntem dışında yapay sinir ağları, bulanık-sinir ağı yapıları veya farklı optimizasyon teknikleri gibi akıllı yapılar, başta MGNI olmak REDS'de farklı kontrol amaçları için kullanılabilirler. Bu çalışmadaki gibi bilgisayar ortamında yapılabilecek modelleme ve analiz çalışmalarıyla REDS'lerle ilgili farklı kontrol çalışmalarına katkı sunulabilir.

\section{Kaynakça}

[1] Tammaruckwattana, S., Ohyama, K. (2013). Modeling and simulation of permanent magnet synchronous generator wind power generation system using boost converter circuit. In 2013 15th European Conference on Power Electronics and Applications (EPE), pp. 1-10.

[2] Sharma, H. K., Samaria, A., \& Gidwani, L. (2017). Designing and performance analysis of controller for PMSG based wind energy conversion system. In 2017 International Conference on Information, Communication, Instrumentation and Control (ICICIC), pp. 1-6. IEEE.

[3] Abbaker, O. (2017). Control of wind turbine for variable speed based on fuzzy-PID controller. Journal of Engineering and Computer Science (JECS), cilt 18(1), pp. 40-51.

[4] Prajapati, K. R. (2019). Application of fuzzy logic for MPPT control in stand-alone wind energy conversion system with a battery storage system. In 2019 IEEE International Conference on Intelligent Techniques in Control, Optimization and Signal Processing (INCOS), pp. 1-6.

[5] Shahi, A., \& Bhattacharjee, C. (2018). A study \& analysis of fuzzy based P\&O MPPT scheme in PMSG based wind turbine. In 2018 Technologies for Smart-City Energy Security and Power (ICSESP), pp. 1-4.

[6] Tiwari, R., \& Babu, N. R. (2016). Fuzzy logic based MPPT for permanent magnet synchronous generator in wind energy conversion system. IFAC-PapersOnLine, cilt 49(1), ss.462-467.

[6] Putri, A. I., Ahn, M., \& Choi, J. (2012). Speed sensorless fuzzy MPPT control of grid-connected PMSG for wind power generation. In 2012 International Conference on Renewable Energy Research and Applications (ICRERA), pp. 1-6.

[7] Ngo, Q. V., Yi, C., \& Nguyen, T. T. (2020). The maximum power point tracking based-control system for small-scale wind turbine using fuzzy logic. International Journal of Electrical and Computer Engineering (IJECE), cilt 10(4), pp. 3927-3935.

[8] Wu, B., Lang, Y., Zargari, N., \& Kouro, S. (2011). Power conversion and control of wind energy systems (Vol. 76). John Wiley \& Sons, New York.

[9] Rolan, A., Luna, A., Vazquez, G., Aguilar, D., \& Azevedo, G. (2009). Modeling of a variable speed wind turbine with a permanent magnet synchronous generator. In 2009 IEEE international symposium on industrial electronics, pp. 734739 .

[10]Patel, M. R. (2005). Wind and solar power systems: design, analysis, and operation. CRC press, New York.

[11]Percin H.B., Caliskan A. (2020). Modeling And Analysıs Of Pitch Angle Control On Varıable Speed Wind Turbines, In 2020 International Engineering and Natural Sciences Conference (IENSC), pp. 131-140.

[12]Sahu, D. (2013). Maximum power extraction for direct driven variable speed wind turbine system using PMSG and fixed pitch angle. In 2013 International Conference on Control, Computing, Communication and Materials (ICCCCM), pp. 1-7.

[13]Abdullah, M. A., Yatim, A. H. M., Tan, C. W., \& Saidur, R. (2012). A review of maximum power point tracking algorithms for wind energy systems. Renewable and sustainable energy reviews, cilt 16(5), ss. 3220-3227.

[14]Thongam, J. S., \& Ouhrouche, M. (2011). MPPT control methods in wind energy conversion systems. Fundamental and advanced topics in wind power, (1), ss. 339-360.

[15]Lee, J., Kim, Y. S. (2016). Sensorless fuzzy-logic-based maximum power point tracking control for a small-scale wind power generation systems with a switched-mode rectifier. IET Renewable Power Generation, cilt 10(2), ss.194-202.

[16]Simoes, M., Bose, B. K., \& Spiegel, R. J. (1997). Design and performance evaluation of a fuzzy-logic-based variablespeed wind generation system. IEEE Transactions on Industry Applications, cilt 33(4), ss. 956-965. 